\title{
Helminth Eggs Detected in Soil Samples of a Possible Toilet Structure Found at the Capital Area of Ancient Baekje Kingdom of Korea
}

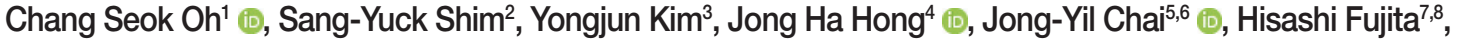 \\ Min Seo,* (D), Dong Hoon Shin ${ }^{10,11, *}$ (B) \\ ${ }^{1}$ Department of Mortuary Science, College of Bio-convergence, Eulji University, Seongnam 13135, Korea; ${ }^{2}$ Kongju National University Museum, \\ Gongju 32588, Korea; ${ }^{3}$ Korea Cultural Heritage Foundation, Seoul 06153, Korea; ${ }^{4}$ nstitute of Korean Archaeology and Ancient History, Kyunghee \\ University, Seoul 02447, Korea; ${ }^{5}$ Department of Tropical Medicine and Parasitology, Seoul National University College of Medicine, Seoul 03080, \\ Korea; ${ }^{6}$ Institute of Parasitic Diseases, Korea Association of Health Promotion, Seoul 07649, Korea; ${ }^{7}$ Research Center for Knowledge Science in \\ Cultural Heritage, Doshisha University, Kyoto 610-0394, Japan; ${ }^{8}$ Paleolabo. Co. Ltd., 335-0016, Saitama, Japan; ${ }^{9}$ Department of Parasitology, \\ Dankook University College of Medicine, Cheonan 31116, Korea; ${ }^{10}$ Bioanthropology and Paleopathology Lab, Institute of Forensic and \\ Anthropological Science, Seoul National University College of Medicine, Seoul 03080, Korea; ${ }^{11}$ Department of Anatomy and Cell Biology, Seoul \\ National University College of Medicine, Seoul 03080, Korea
}

\begin{abstract}
Although research conducted in East Asia has uncovered parasite eggs from ancient toilets or cesspits, data accumulated to date needs to be supplemented by more archaeoparasitological studies. We examined a total of 21 soil samples from a toilet-like structure at the Hwajisan site, a Baekje-period royal villa, in present-day Korea. At least 4 species of helminth eggs, i.e., Trichuris trichiura, Ascaris lumbricoides, Clonorchis sinensis, and Trichuris sp. (or Trichuris vulpis) were detected in 3 sediment samples of the structure that was likely a toilet used by Baekje nobles. The eggs of $T$. trichiura were found in all 3 samples (no. 1, 4, and 5); and A. lumbricoides eggs were detected in 2 samples (no. 4 and 5). C. sinensis and T. vulpis-like eggs were found in no. 5 sample. From the findings of this study, we can suppose that the soil-transmitted helminths were prevalent in ancient Korean people, including the nobles of Baekje Kingdom during the 5th to 7 th century.
\end{abstract}

Key words: Trichuris trichiura, Ascaris lumbricoides, Clonorchis sinensis, parasite egg, paleoparasitology, flush toilet, ancient kingdom, Baekje

\section{INTRODUCTION}

In ancient East Asian realms, the prevalence of parasite infections was high because fertilizer based on human excrement was widely used before modernization [1-4]. The analysis of toilet sediments is particularly important in archaeoparasitology, as disposal of human waste was central to the infection status of parasites and sanitary conditions of ancient societies [1]. The question of what kinds of parasites ancient peoples were infected with can be answered by examination of specimens from toilets discovered at the archaeological sites.

Over the past several decades, studies of ancient humanwaste reservoirs have been conducted in East Asian countries.

\footnotetext{
- Received 19 May 2021, revised 28 July 2021, accepted 29 July 2021.

*Corresponding authors (bbbenj@naver.com; cuteminjae@gmail.com)

(c) 2021, Korean Society for Parasitology and Tropical Medicine

This is an Open Access article distributed under the terms of the Creative Commons Attribution Non-Commercial License (https://creativecommons.org/licenses/by-nc/4.0 which permits unrestricted non-commercial use, distribution, and reproduction in any medium, provided the original work is properly cited.
}

In cases where the toilet-like structure was discovered at excavation site, parasitological study can be made by analysis of sediments therein [1-4]. Archaeoparasitologists in Korea and Japan, for example, have detected parasite eggs in samples from putative cesspits or flush toilets $[1,3]$. In Japan, researchers discovered human coprolites in structures that had been used as a toilet or dung heap at the time, a conclusion verified by parasitological examinations $[3,5,6]$. From Korea, there have also been parasitological reports on structures apparently correspondent to flush toilets or cesspits $[1,7]$.

Notwithstanding, the information associated specifically with ancient toilets and parasite eggs that were found therein has yet to be fully attained in East Asian countries. The data accumulated to date needs to be supplemented by more parasitological studies on the samples from ancient structures that might have served as flush toilets or cesspits in East Asia. In this study, to obtain the information of helminthic infections at that time in Korea, we thus examined the soil samples collected at a possible flush toilet of a royal villa of the Baekje 
Kingdom during the 5th to 7th century.

\section{CASE DESCRIPTION}

Our parasitological study was conducted at the Hwajisan remains of Buyeo (扶餘花枝山遺蹟) (36¹6'12"N, 126 $56^{\circ} 53^{\prime} \mathrm{E}$ ) (Fig. 1). Archaeologists presumed that this site might have been once a royal villa of the Baekje Kingdom during the 5th

A
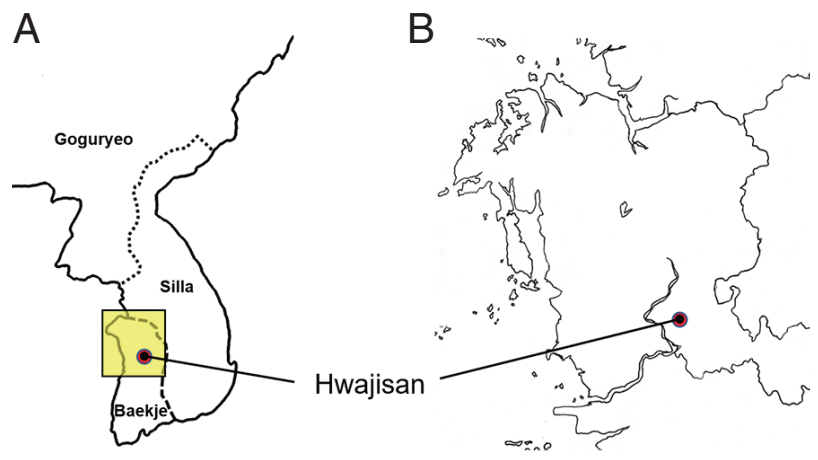

Fig. 1. The location of Hwajisan site. (A) The 6th century map of Korea. The territory of ancient Korean kingdoms (Baekje, Goguryeo and Silla) is marked. (B) Magnified image of the yellow rectangle area in (A). Red dot indicates Hwajisan site. to 7th century. The estimated date was confirmed by radiocarbon dating analysis $[8,9]$. A total of 21 soil samples were collected for this study. Specimens were obtained from the geological strata of a structure presumed to be a toilet and its associated-water-channel remains (Fig. 2). The detailed information of sampling places in Fig. 2 are also available in Fig. 3.

We sampled at the following specific places: a wooden structure (sample no. 1 to 7), water-channel remains (no. 8 to 18 ), and the topsoil layers of a heating facility (no. 19 to 21 ) (Fig. 3). Among them, our archaeologists speculated that the wooden structure might have been a toilet used during the Baekje period (Fig. $3 \mathrm{~A}$ ) because the structure is somewhat reminiscent of ancient flush toilets discovered in Japan $[3,5,6]$. When sediment samples (no. 1 to 7 ) were taken there, sample no. 1, 4 , and 5 appeared to contain large amounts of organic matter, judging from its dark color and viscosity. As for the waterchannel remains, sample no. 8 to 11 were obtained from the layer at which water presumably had entered the toilet-like wooden structure (Fig. 3A, B). Sample no. 13 to 18 (Fig. 3C) were also sampled from the layers where the waterway exited the wooden structure. Sample no. 19 to 21 (Fig. 3D) were collected at the area where the heating facility existed. To prevent
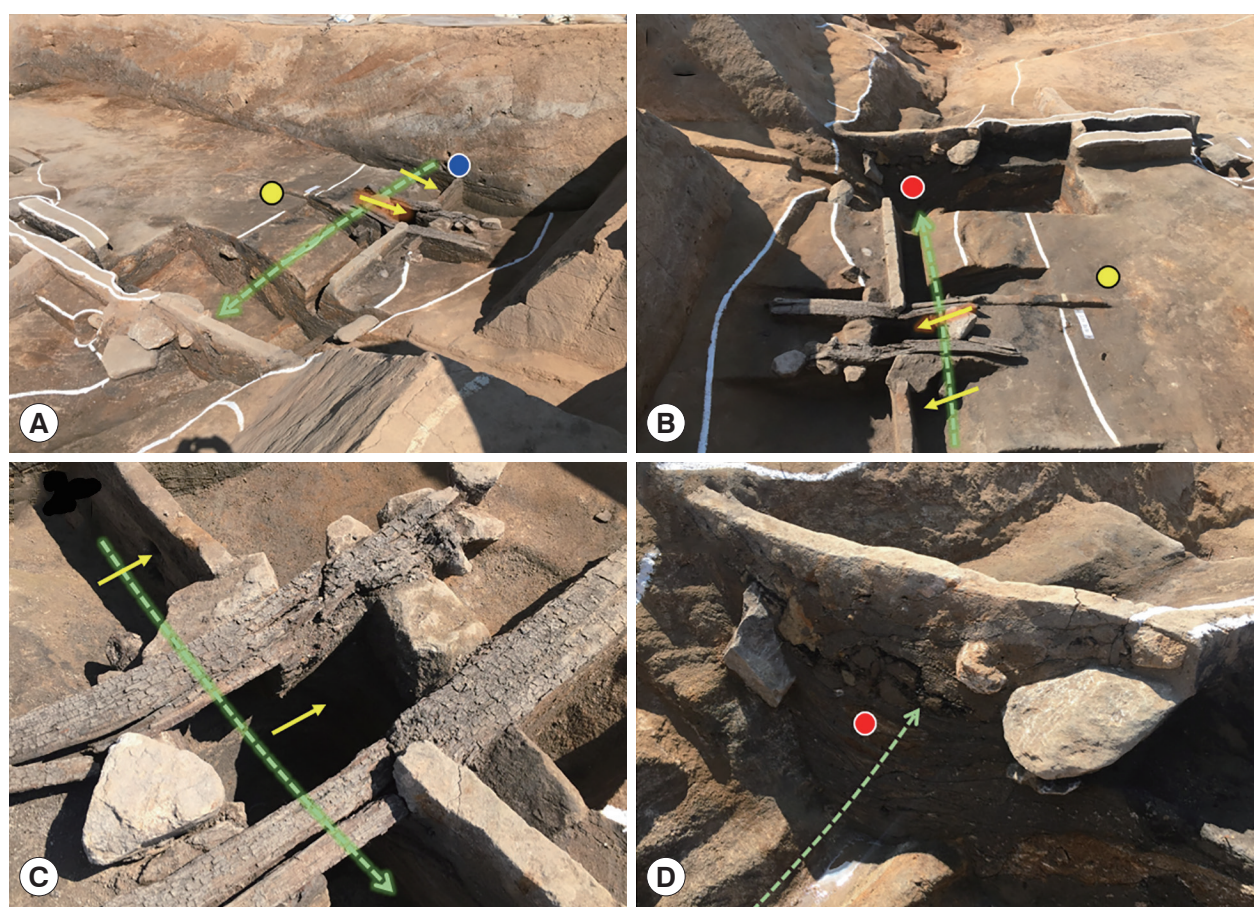

Fig. 2. (A) to (D) Hwajisan excavation site and the places where sampling was done. Yellow arrows in (A) to (C) indicate the sampling places for a wooden structure presumed to be an ancient toilet (sample no. 1 to 7) and its associated water channel (no. 8 and 9). The sampling details are summarized in Fig. 3. Green dotted line arrow in (A) to (D) indicate the direction in which the water flows. Yellow (no. 19 to 21), blue (no. 10 and 11), and red dots (no. 13 to 18) indicate the sedimentary and topsoil layers of sampling. 


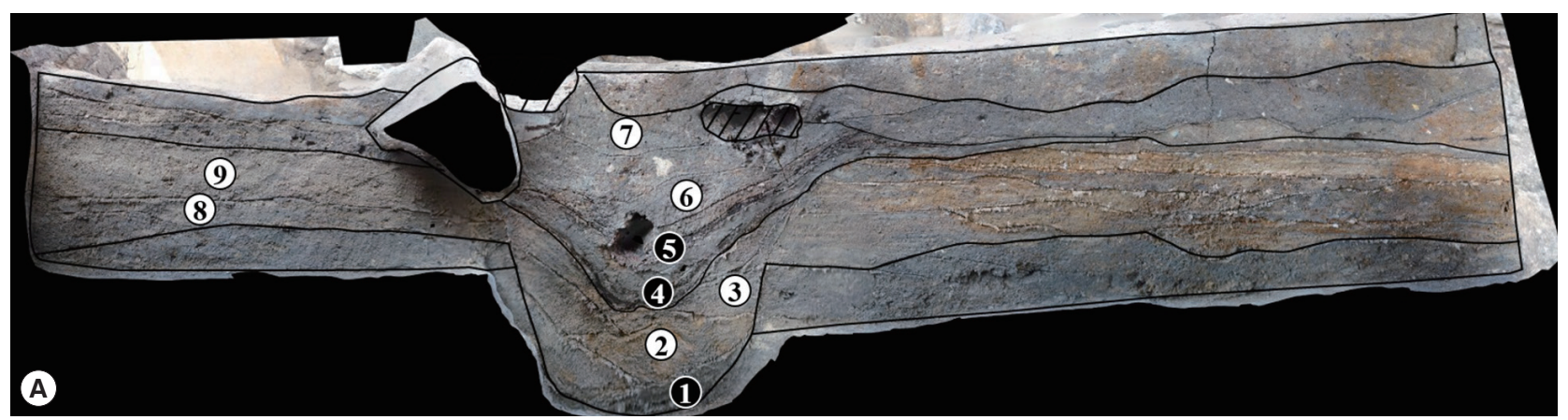

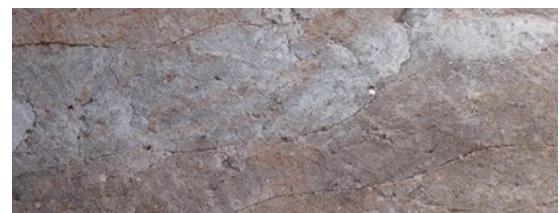

(11)

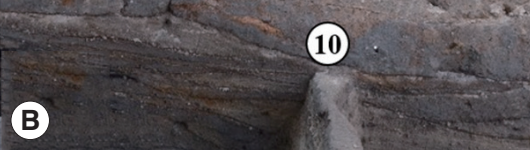

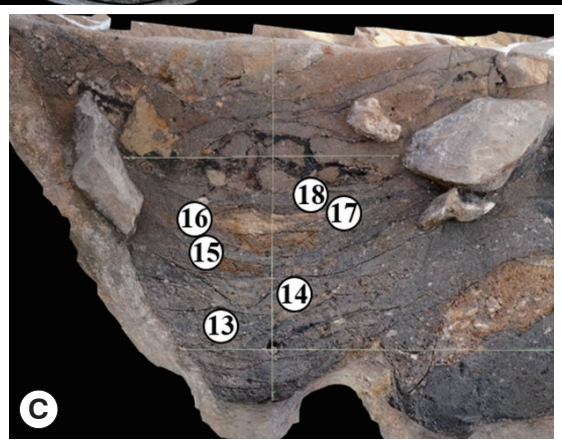

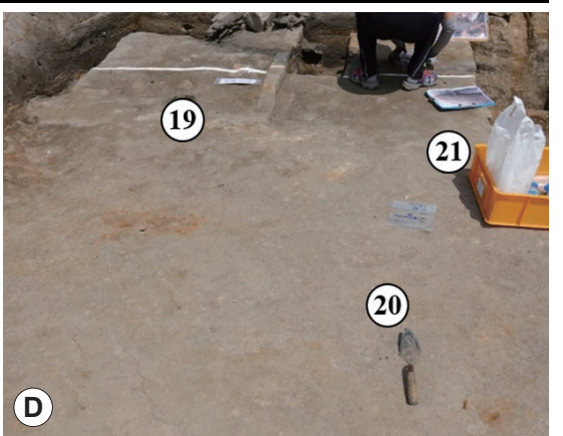

Fig. 3. The details of sampling places in Hwajisan site. (A) The place indicated by yellow arrows in Fig. 2. Sample no. 1 to 7 for the samples from a wooden structure presumed to be an ancient toilet; no. 8 and 9 for a water channel inflow. Black dots in (A) mean the samples showing positivity for parasitological examination. (B) The sampling place indicated by blue dot (no. 10 and 11) in Fig. 2. (C) The sampling place indicated by red dot (no. 13 to 18) in Fig. 2. (D) The sampling place indicated by yellow dot (no. 19 to 21 ) in Fig. 2.

contamination from the environment during sampling, sterilized masks, gowns, head caps, gloves, and sampling tubes were used.

Each collected specimen (10 g) was re-hydrated in trisodium-phosphate-buffered saline (0.5\%) [10-12]. After filtering through multiple layered gauze, precipitation for a day, and removal of the supernatant, the precipitate was dissolved in the buffer (up to $20 \mathrm{ml}$ ) again. Total $20 \mu \mathrm{l}$ of the final solution was dropped onto 10 slides, and thus, a total of $200 \mu$ l of the sample was examined under light microscopy (BH-2; Olympus, Tokyo, Japan) [13]. The number of helminth eggs per gram (EPG) was estimated, and the egg sizes were measured as described in Han et al. [11].

In the specimens (no. 1, 4, 5) collected from the Hwajisan site, the eggs of various parasite species were observed (Fig. 4). Trichuris trichiura eggs were found in every sample. Ascaris lumbricoides eggs were discovered in samples of no. 1 and 4. In sample no. 5, the eggs of Trichuris sp. (or T. vulpis) and Clonorchis sinensis were found. Upon discovery of those eggs in the specimens, we concurred with archaeologists' hypothesis that the wooden structure had functioned as a toilet during the Baekje period. Meanwhile, none of the specimens from the water channel (no. 8 to 18) and heating facility (no. 19 to 21) showed any parasite eggs. The average-size and EPG data on the ancient parasite eggs are provided in Table 1.

\section{DISCUSSION}

The Hwajisan site is believed to have been the Baekje king's royal villa after the capital of his realm was moved to Buyeo in 538CE. In the specimens collected from various places at the site, we found ancient eggs of T. trichiura and A. lumbricoides, which are the 2 parasite species commonly reported from our archaeoparasitological studies conducted thus far in Korea [14]. Indeed, our parasitological results showed positivity for the samples (no. 1, 4, and 5) corresponding to sediment layers accumulated inside the wooden structure, a presumptive primitive form of flush toilet.

We found that the wooden structure at the Hwajisan site was connected to a waterway. If this were in fact a Baekje-period flush toilet, the feces would have settled in the structure's sediments while the water inflow into the structure pushed the dirty water outside. We note that parasitic eggs were not discovered in the waterway samples of this study, which means 



Fig. 4. Ancient parasite eggs found in the samples (no. 1, 4 and 5) from wooden structure presumed to be an ancient toilet at Hwajisan site. Eggs of (A) Trichuris trichiura in no. 1, (B) and (C) T. trichiura in no. 4, (D) Ascaris lumbricoides in no. 4, (E) T. trichiura in no. 5, (F) A. lumbricoides in no. 5, (G) Clonorchis sinensis in no. 5, and (H) Trichuris sp. (or T. vulpis) in no. 5 sample. Scale Bars $=20 \mu \mathrm{m}$.

Table 1. The size and number of eggs (per a gram) in the samples

\begin{tabular}{|c|c|c|c|}
\hline \multirow{2}{*}{$\begin{array}{c}\text { Sample } \\
\text { no. }\end{array}$} & \multirow{2}{*}{$\begin{array}{l}\text { Helminth eggs } \\
\text { detected }\end{array}$} & Size of eggs $(\mu \mathrm{m})$ & \multirow{2}{*}{ EPG } \\
\hline & & Length $\times$ Width & \\
\hline 1 & Trichuris trichiura & $52.5 \pm 0.0 \times 27.5 \pm 0.0$ & 36.4 \\
\hline \multirow[t]{2}{*}{4} & T. trichiura & $51.3 \pm 1.8 \times 54.2 \pm 0.0$ & 54.2 \\
\hline & Ascaris lumbricoides & $72.5 \pm 0.0 \times 47.5 \pm 0.0$ & 36.1 \\
\hline \multirow[t]{4}{*}{5} & T. trichiura & $48.8 \pm 1.4 \times 25.0 \pm 0.0$ & 185.8 \\
\hline & A. lumbricoides & $68.3 \pm 3.8 \times 50.0 \pm 4.3$ & 54.6 \\
\hline & Clonorchis sinensis ${ }^{\mathrm{a}}$ & $25.0 \pm 0.0 \times 16.3 \pm 1.8$ & 21.9 \\
\hline & Trichuris sp. (or T. vulpis) ${ }^{b}$ & $65.0 \pm 0.0 \times 47.5 \pm 0.0$ & 10.9 \\
\hline
\end{tabular}

a2 eggs; ${ }^{\text {b1 }}$ egg.

that upper water flow might have had a smaller number of parasitic eggs than the floor of the toilet-like structure. This is to say, that parasite eggs were found exclusively at the area of what was believed to have been an ancient toilet.

In Japan, by parasitological and archaeological evidences, Masaaki Kanehara (Nara University of Education) and others have confirmed the presence of cesspits or flush toilets at archaeological sites. They speculated that cesspits reported from the ancient Tsukusikan (筑紫館) and Nagaokakyo (長岡京) sites might have been related to the use of human manure in farming $[3,5]$. The discovery of a flush toilet was also reported for the excavation of Heijo-Kyo (平城京), the capital city of ancient Japan. There, the side gutters in the streets served as sewers for removal of toilet excrement or domestic wastewater [3]. Reports on the Fujiwarakyo (藤原京) and Akita castle (秋田城 跡) sites include the discoveries of ancient Japanese flush toilets as well $[5,6]$.

Cesspit and flush toilets have also been found in recent ar- chaeological excavations of Korea. Many parasite eggs were observed in sediments from ancient cesspits or dung heaps unearthed at Buyeo, the capital of the Baekje Kingdom [1]. Meanwhile, in 2004, Korean archaeologists reported a flush toilet-like structure at one of the royal palace sites (Wanggung-ri site; 王宮里遺跡). The flush toilet of the Baekje Kingdom was likely connected by a sewage canal to the palace perimeter [7]. Apparent flush toilet was also discovered in the course of another archaeological investigation, this one at a royal palace of the Silla Kingdom (57 BCE to 935 CE; Donggung site; 東宮遺 跡) [15]. Combining this and existing reports in Korea and Japan, we presume that similar sanitary arrangements might have been used in ancient East Asia; and so, those countries in ancient times shared a tradition of using flush toilets.

In this study, we can propose that the soil-transmitted helminths were prevalent in the Baekje people, including the nobles during the 5th to 7th century. The present parasitological study also yields evidence that a wooden structure unearthed at the Hwajisan site might have been used as a flush toilet during the Baekje period. Our report strongly proposes that the flush toilets could be widely utilized by Korean nobles of the 5th to 7th century (at the latest). To comprehend the history of ancient parasitism more comprehensively, future achievements need to be supplemented by more parasitological studies on the specimens from archaeological sites in Korea.

\section{ACKNOWLEDGEMENT}

This research was supported by Basic Science Research Pro- 
gram through the National Research Foundation of Korea by the Ministry of Science and ICT (2020R1A2C1010708).

\section{CONFLICT OF INTERSET}

The authors declare no competing interests.

\section{REFERENCES}

1. Shin DH, Shim SY, Kim MJ, Oh CS, Lee MH, Jung SB, Lee GI, Chai JY, Seo M. V-shaped pits in regions of ancient Baekje Kingdom paleoparasitologically confirmed as likely human-waste reservoirs. Korean J Parasitol 2014; 52: 569-573. https://doi.org/ 10.3347/kjp.2014.52.5.569

2. Kurosaki S. The Toilet Features of the Fujiwara Palace Site. Nabunken. Nara, Japan. 1992.

3. Matsui A, Kanehara M, Kanehara M. Palaeoparasitology in Japan-discovery of toilet features. Mem Inst Oswaldo Cruz 2003; 98 (suppl): 127-136. https://doi.org/10.1590/S0074-02762003000900019

4. Ki HC, Bae JH, Shin DH. Historical study on factors inducing soil- transmitted helminth infection among people of old Seoul city during Joseon dynasty. Korean J Med Hist 2013; 22: 89-132 (in Korean). https://doi.org/10.13081/kjmh.2013.22.89

5. Folk Museum of Ota City. Toilet Archaeology. Tokyo, Japan. Tokyo Bizyutsu Co. Ltd. 1997.

6. Ito T. Results of excavations at the Akita castle site. Nihon koukogaku 2000; 7: 127-137 (In Japanese). https://doi.org/10.11215/ nihonkokogaku1994.7.10_127

7. Buyeo National Research Institute of Cultural Heritage. The Achievement and Significance of Excavation on the Wanggungri
Site in Iksan. Buyeo, Korea. Buyeo National Research Institute of Cultural Heritage. 2009.

8. The Baekje Cultural Foundation. Archaeological Site in Hwajisan Mountain, Buyeo: 2nd and 3rd Excavation in 2015-2016. Buyeo, Korea. The Baekje Cultural Foundation. 2018 (in Korean).

9. The Baekje Cultural Foundation. Archaeological site in Hwajisan Mountain, Buyeo: 5th Excavation in 2018. Buyeo, Korea. The Baekje Cultural Foundation. 2020 (in Korean).

10. Van Cleave HJ, Ross JA. A method for reclaiming dried zoological specimens. Science 1947; 105: 318. https://doi.org/10.1126/ science.105.2725.318

11. Han ET, Guk SM, Kim JL, Jeong HJ, Kim SN, Chai JY. Detection of parasite eggs from archaeological excavations in the Republic of Korea. Mem Inst Oswaldo Cruz 2003; 98 (suppl): 123-126. https://doi.org/10.1590/S0074-02762003000900018

12. Reinhard K, Urban O. Diagnosing ancient diphyllobothriasis from Chinchorro mummies. Mem Inst Oswaldo Cruz 2003; 98 (suppl): 191-193. https://doi.org/10.1590/S0074-02762003000900028

13. Seo M, Oh CS, Hong JH, Chai JY, Cha SC, Bang Y, Cha IG, Wi YG, Park JM, Shin DH. Estimation of parasite infection prevalence of Joseon people by paleoparasitological data updates from the ancient feces of pre-modern Korean mummies. Anthropol Sci 2017; 125: 9-14. https://doi.org/10.1537/ase.160920

14. Seo M, Hong JH, Reinhard K, Shin DH. Archaeoparasitology of Korean Mummies. In Shin DH, Bianucci R eds. The Handbook of Mummy Studies. Springer. Singapore, 2021, pp 1-21. https:// doi.org/10.1007/978-981-15-1614-6_14-2

15. Gyeongju National Research Institute of Cultural Heritage. Excavation Report III: Donggung Palace and Wolji Pond in Gyeongju. Gyeongju, Korea. Gyeongju National Research Institute of Cultural Heritage. 2019. 
